\title{
Hazard assessment of storm events for The Battery, New York
}

ARTICLE in OCEAN \& COASTAL MANAGEMENT • NOVEMBER 2015

Impact Factor: 1.75 · DOI: 10.1016/j.ocecoaman.2015.11.006

4 AUTHORS, INCLUDING:

José L. S. Pinho

University of Minho

88 PUBLICATIONS 142 CITATIONS

SEE PROFILE
José S. Antunes do Carmo

University of Coimbra

143 PUBLICATIONS 438 CITATIONS

SEE PROFILE 
Dear Author,

Please, note that changes made to the HTML content will be added to the article before publication, but are not reflected in this PDF.

Note also that this file should not be used for submitting corrections. 


\title{
Hazard assessment of storm events for the battery, New York
}

\author{
Q3 Mariana Peixoto Gomes ${ }^{\text {a }}$, José Luís Pinho a, José S. Antunes do Carmo ${ }^{\text {b, }}$, Lara Santos ${ }^{\text {b }}$ \\ a University of Minho, Braga, Portugal \\ ${ }^{\mathrm{b}}$ University of Coimbra, Coimbra, Portugal
}

\section{A R T I C L E I N F O}

Article history:

Received 1 October 2014

Received in revised form

6 November 2015

Accepted 8 November 2015

Available online $\mathrm{xxx}$

\section{Keywords:}

Cyclones

Storm surges

Hazard assessment

Numerical modeling

New York coast

Delft3D

\begin{abstract}
A B S T R A C T
The environmental and socio-economic importance of coastal areas is widely recognized, but at present these areas face severe weaknesses and high-risk situations. The increased demand and growing human occupation of coastal zones have greatly contributed to exacerbating such weaknesses. Today, throughout the world, in all countries with coastal regions, episodes of waves overtopping and coastal flooding are frequent. These episodes are usually responsible for property losses and often put human lives at risk. The floods are caused by coastal storms primarily due to the action of very strong winds. The propagation of these storms towards the coast induces high water levels. It is expected that climate change phenomena will contribute to the intensification of coastal storms. In this context, an estimation of coastal flooding hazards is of paramount importance for the planning and management of coastal zones. Consequently, carrying out a series of storm scenarios and analyzing their impacts through numerical modeling is of prime interest to coastal decision-makers. Firstly, throughout this work, historical storm tracks and intensities are characterized for the northeastern region of United States coast, in terms of probability of occurrence. Secondly, several storm events with high potential of occurrence are generated using a specific tool of DelftDashboard interface for Delft3D software. Hydrodynamic models are then used to generate ensemble simulations to assess storms' effects on coastal water levels. For the United States' northeastern coast, a highly refined regional domain is considered surrounding the area of The Battery, New York, situated in New York Harbor. Based on statistical data of numerical modeling results, a review of the impact of coastal storms to different locations within the study area is performed. ๑) 2015 Published by Elsevier Ltd.
\end{abstract}

\section{Introduction}

Coastal zones are of major importance due to their intrinsic environmental and socio-economic characteristics, mainly related with their high demographic densities (residents and tourists during the bathing season) and natural resources. These areas are affected by natural disasters mainly caused by weather events, including coastal storms that can induce storm surges. A storm surge is an irregular rise in sea level generated by a tropical cyclone's wind, waves, and low atmospheric pressure. Storm tides are also induced when the combination of astronomic high tides and the storm surge occurs, causing high elevations of the water surface (FEMA, 2003).

Tropical storms and wind storms, constituting about $38 \%$ of the total natural disasters, are responsible for 19\% of deaths, $39 \%$ of overall losses and 72\% of global insured losses (Kron, 2012). Such

\footnotetext{
* Corresponding author.

E-mail address: jsacarmo@dec.uc.pt (J.S. Antunes do Carmo).
}

events can cause or worsen various risk situations, such as episodes of overtopping of coastal defenses, coastal flooding with local water surface elevation anomalies reaching up to several meters (Kron, 2012), coastal erosion and loss of territory, resulting in countless damages including loss of property and human lives.

Variations of storm surge heights depend on numerous factors, such as the tropical storm category, forward speed, radius of maximum winds (RMW), proximity of the storm trajectory to the coastal zone, bathymetry, coastal geomorphology and shape of the coastline (Nott, 2006). However, the storm's forward speed can be considered one of the most important factors presenting a greater influence than the wind intensity or the RMW (Rego and Li, 2009). Fast moving storms cause higher surges over open coast and lower surges in protected estuaries, while slower moving storms usually result in greater flooding in estuaries and smaller values of flooding along the coast.

Thus, numerical modeling systems are essential for a detailed forecast of the possible impacts of coastal storms in terms of water levels, flood area and wind speed. Such studies should allow for the 
identification of the most vulnerable areas and assist in proper planning and management of existing coastal resources in the long term. In the future, such scenarios may worsen due to climate change occurrences, considering the possible rise in sea level (Klemas, 2009), as well as coastal storms with greater frequency and intensity (Weisse et al., 2012).

Tropical cyclones usually form between $5^{\circ}$ and $30^{\circ} \mathrm{N}$ latitude, usually moving toward the west. This $5^{\circ} \mathrm{N}$ formation is required in order to produce a minimum of Coriolis force required for the development of a tropical cyclone (Landsea and Goldenberg, 2004). In the North Atlantic Basin, tropical storms occur with a certain seasonality (mainly concentrated between August and September) and usually affect the Eastern United States and Canada (between 1 and 2 storms every year) and occasionally also Western Europe (one storm in 1 or 2 years) (Hart and Evans, 2001; Keim et al., 2004). In the case of the Eastern United States, the Atlantic "hurricane season" runs from June 1st to November 30th (Landsea and Goldenberg, 2004). When reaching $30^{\circ} \mathrm{N}$ latitude, the tropical cyclones often move northwest affecting the Eastern United States and Canada.

As the tropical cyclone develops, it reaches a point where it transitions from a tropical system to an extratropical system. A tropical transition is referred to as a tropical cyclone that moves over colder water and into strong shear at high latitudes (Hart and Evans, 2001). The term 'extratropical' is used to indicate that a cyclone has lost its "tropical" characteristics; it implies both polarward displacement of the cyclone and the conversion of the cyclone's primary energy source from the release of latent heat of condensation to baroclinic (NHC, 2015). The cyclone's source of energy becomes baroclinic, meaning that it results from the temperature contrast between cold and warm air masses. It should be noted that cyclones can become extratropical and still retain winds of hurricane (64 knots) or tropical storm (33 knots) force. The probability of cyclone's transitioning is during the months of September and October, when transiting 50\% of all Atlantic tropical cyclones (Hart and Evans, 2001).

The sudden change from a tropical to an extratropical cyclone means a sudden change to the structure of the cyclone. Drastic variations of storm speed, direction, and position are a result of this structural change. As the systems become extratropical, rapid fluctuations of a storm's wind field intensity and an outward expansion of storm force is associated. The transformation of tropical cyclones to extratropical cyclones, and vice versa, is in fact a challenging forecasting problem. Results from general circulation models, GCMs, about future tropical cyclone climatology are mixed, but there is a suggestion that extratropical storms could decrease slightly, but that there is still potential for the generation of more intense hurricanes (. There is also a strong suggestion that extratropical systems in the North Atlantic Basin have declined overall over the past 50-100 years, but there is an increase in frequency of really powerful storms (Keim et al., 2004). This is certainity an important factor to consider in terms of coastal management and emergency evacuation plans.

The Battery, New York, is located in lower Manhattan. Manhattan is the most populated New York county in the United States. Southern Manhattan alone has a population density greater than the citywide average, containing a population of nearly 200,000 inhabitants. Southern Manhattan's coastal areas are crucial to New York's evolution as a global city. Its waterfront can become a valuable asset, as home for residential and commercial office development; nevertheless, its low-lying coastal edges remain vulnerable to extreme weather. Southern Manhattan contains the fourth largest business district in the United States. It is positioned at the heart of the New York's transportation networks, such as subway lines, heliports, ferry landings, power facilities, and healthcare institutions (Bloomberg, 2013). In 2013, the American
Association of Port Authorities, AAPA, ranked the Port of New York/ New Jersey as the second busiest port in the United Stated, based on total imports and exports by weight (American Association of Port Authorities (2014)).

The NYC Panel on Climate Change, NPCC, projects that New York City could see up to $0.76 \mathrm{~m}$ of sea level rise by the 2050s as well as triple the number of days above $90{ }^{\circ} \mathrm{F}$ (NPCC, 2013). The Preliminary Work Maps released by FEMA in June 2013 for the 2020s predict that the flooded area could expand to $153 \mathrm{~km}^{2}$, encompassing 88,000 buildings. That magnitude of sea level rise can threaten communities residing in low-lying New York areas and make flooding as severe as today's 100-year storm at The Battery up to five times more likely. New York City in collaboration with the Swiss Reinsurance Company has performed an initial lossmodeling, which indicates that due to sea level rise, NYC is $17 \%$ more likely in the 2020s to see a storm that causes nineteen billion dollars in damages, as Superstorm Sandy did (Bloomberg, 2013).

The main objective of this work is to study storm surge occurrences in the northeastern United States coast. The ongoing population increase along the coast, verified in the United States' eastern coast only exacerbates the importance of the effects of eventual coastal flooding resulting from storm surges. This work seeks to identify and analyze the impact of historic tropical systems that affect the western end of the Northern Atlantic Basin. The characteristics and pathways of tropical cyclones will be explored as well as an assessment of their associated weather conditions. The main purpose deals with the use of practical applications with the main objective of generating useful knowledge for advancements in the hydrodynamic modeling of storm surges. Numerical modeling systems are essential for a correct forecasting of the impact of coastal storms. Studying important aspects like the wind speed, water levels and possible flood regions make it possible to define the most vulnerable areas. At present, there are hydrodynamic tools available to allow for the simulation of storms effects, provided that one knows their associated wind and atmospheric characteristics. They can be estimated based on the prediction of the velocity, atmospheric pressures, and trajectory of the storm's center. With this, it is then possible to establish proper planning and management of the coastal areas in the future. It is important to study various scenarios to identify the more susceptible areas and manage existing coastal resources for long term planning.

In the first phase, the historical coastal storms that occurred near the New York coast were collected, using the National Oceanic and Atmospheric Administration (NOAA) database as well as the University of Hawaii Sea Level Center's database. Through a physical viewpoint, a historical hazard analysis can be used as a contribution for further analysis on risk assessment and aid in the development of risk plans. With this work, a better understanding of how tropical systems behave in the North Atlantic Basin, on its westward extremity, will be given. The application of Delft Dashboard and Delft3D-FLOW will be explored for the simulation of the effect of storms on the surface elevation of the water along the coast. The creation of numerical tools for storm simulations is possible with the Delft Dashboard software based on the grid generation, definition of the corresponding boundary conditions, generation of the trajectory's wind field and the storm's center wind speed. Historical storms affecting the US's northeastern coast (encompassing the Hudson River mouth) will be simulated and results compared to the storms' recorded values.

Consequently, in a second phase, the definition and subsequent simulation of probabilistic ensemble forecasts will be created to assess the vulnerability of the coast to storminess. A methodology will be presented that considers hypothetical scenarios resulting from geographical shifts of the already generated historical tropical systems. By comparing the different possible outcomes, one can 
examine how likely a particular weather event will be, and better analyze its consequences so as to better prepare coastal emergency plans, for example. The main goal is to create a large range of trajectories that demonstrate correlations between one another, but at the same time produce different results.

\section{Material and methods}

As stated above, the historical coastal storms that occurred near the New York coast were collected. Afterwards, taking into account the Saffir-Simpson Scale (IM, 2008), the probability of occurrence of the different storm categories in this area was obtained.

The second phase was focused on the simulation of scenarios using a numerical model for different trajectories and intensities of the collected historical storms. A very fine grid was adopted, covering an area extensive enough so that region of New York Harbor would be clear to distinguish and so that the area under analysis would be far enough away from the open boundaries to minimize discretization errors. Because there is available data for the New York coast, the application of DelftDashboard's Tropical Cyclone Toolbox to this region allows for the comparison of the predicted results to actual observed results. The validation of the tropical systems in this region subsequently allows for a greater confidence in its application in similar locations.

Storm water levels were simulated using the hydrodynamic numerical program, Delft3D-FLOW (Deltares, 2011). This multidimensional, hydrodynamic (and transport) simulation program considers different physical phenomena, such as Coriolis force, water density gradients, tidal flow analysis, currents induced by wind and pressure gradients. Pre-processing tasks were supported by the above mentioned tool, DelftDashboard. This tool permits for the definition of the model grid, its bathymetry, open boundary conditions and the generation of the spiderweb wind field (Deltares, 2011, 2012) associated with each simulated storm.

Delft3D solves the nonlinear shallow water equations in two and three dimensions. These equations are derived by averaging the full Navier-Stokes equations in the vertical direction, assuming that the horizontal scale is much larger than the vertical. The vertical accelerations are assumed to be much smaller than the horizontal ones, which reduces the vertical momentum equation to a hydrostatic pressure equation. For a three dimensional shallow water model, the flow domain is made up of a horizontal plane of a limited area composed of open and closed boundaries, and in the vertical direction a number of layers are defined. The continuity equation is,

$$
\begin{aligned}
& \frac{\partial \zeta}{\partial t}+\frac{1}{\sqrt{G_{\xi \xi}} \sqrt{G_{\eta \eta}}} \frac{\partial\left[(d+\zeta) U \sqrt{G_{\eta \eta}}\right]}{\partial \xi} \\
& +\frac{1}{\sqrt{G_{\xi \xi}} \sqrt{G_{\eta \eta}}} \frac{\partial\left[(d+\zeta) V \sqrt{G_{\xi \xi}}\right]}{\partial \eta}=Q
\end{aligned}
$$

where, $\xi, \eta$ are the Cartesian coordinates, $\zeta$ is the free surface elevation above a reference plane, $\mathrm{d}$ is the depth below the free surface, $\sqrt{G_{\xi \xi}}$ and $\sqrt{G_{\eta \eta}}$ are coefficients used to transform curvilinear coordinates to rectangular grid, $\mathrm{U}$ and $\mathrm{V}$ are the depthintegrated components of the velocity in the computational domain and $\mathrm{Q}$ is the source or sink term which is defined as,

$Q=H \int_{-1}^{0}\left(q_{\text {in }}-q_{\text {out }}\right) d \sigma+P-E$

in which, $H=d+\zeta, \mathrm{P}$ is the precipitation, $\mathrm{E}$ is the evaporation, $q_{i n}$ is the source of water, and $q_{\text {out }}$ is the sink for water. Momentum equations in horizontal direction present the form:

$$
\begin{aligned}
\frac{\partial u}{\partial t}= & -\frac{u}{\sqrt{G_{\xi \xi}}} \frac{\partial u}{\partial \xi}-\frac{v}{\sqrt{G_{\eta \eta}}} \frac{\partial u}{\partial \eta}-\frac{\omega}{d+\zeta} \frac{\partial u}{\partial \sigma}+\frac{v^{2}}{\sqrt{G_{\xi \xi}} \sqrt{G_{\eta \eta}}} \frac{\partial \sqrt{G_{\eta \eta}}}{\partial \xi} \\
& -\frac{u v}{\sqrt{G_{\xi \xi}} \sqrt{G_{\eta \eta}}} \frac{\partial \sqrt{G_{\xi \xi}}}{\partial \eta}+f v+F_{\xi}+M_{\xi}-\frac{1}{p_{o} \sqrt{G_{\xi \xi}}} P_{\xi} \\
& +\frac{1}{(d+\zeta)^{2}} \frac{\partial}{\partial \sigma}\left(v_{\mathrm{V}} \frac{\partial u}{\partial \sigma}\right) \\
\frac{\partial v}{\partial t}= & -\frac{u}{\sqrt{G_{\xi \xi}}} \frac{\partial v}{\partial \xi}-\frac{v}{\sqrt{G_{\eta \eta}}} \frac{\partial v}{\partial \eta}-\frac{\omega}{d+\zeta} \frac{v}{\partial \sigma}-\frac{u v}{\sqrt{G_{\xi \xi}} \sqrt{G_{\eta \eta}}} \frac{\partial \sqrt{G_{\eta \eta}}}{\partial \xi} \\
& +\frac{u^{2}}{\sqrt{G_{\xi \xi}} \sqrt{G_{\eta \eta}}} \frac{\partial \sqrt{G_{\xi \xi}}}{\partial \eta}-f u+F_{\eta}+M_{\eta}-\frac{1}{p_{o} \sqrt{G_{\eta \eta}}} P_{\eta} \\
& +\frac{1}{(d+\zeta)^{2}} \frac{\partial}{\partial \sigma}\left(v_{\mathrm{V}} \frac{\partial v}{\partial \sigma}\right)
\end{aligned}
$$

where $\sigma$ vertical coordinate is adopted, $u$ and $v$ are the eastward and northward velocity in the physical domain, respectively, $\omega$ is the vertical velocity adapted to the $\sigma$-plane, $v_{\mathrm{V}}$ is the vertical eddy velocity coefficient, $F_{\xi}$ and $F_{\eta}$ represent the unbalance of the horizontal Reynold's stresses, $M_{\xi}$ and $M_{\eta}$ are the contribution due to external sources or sinks, $P_{\xi}$ and $P_{\eta}$ are the pressure terms, and $f$ is the Coriolis coefficient. The vertical velocity reads

$$
\begin{aligned}
w=\omega & +\frac{1}{\sqrt{G_{\xi \xi}} \sqrt{G_{\eta \eta}}}\left[u \sqrt{G_{\eta \eta}}\left(\sigma \frac{\delta H}{\delta \xi}+\frac{\delta \zeta}{\delta \xi}\right)+v \sqrt{G_{\xi \xi}}\left(\frac{\delta H}{\delta \eta}+\frac{\delta \zeta}{\delta \eta}\right)\right] \\
& +\left(\sigma \frac{\delta H}{\delta t}+\frac{\zeta}{\delta t}\right)
\end{aligned}
$$

in which $\omega$ is the vertical velocity adapted to the $\sigma$-plane calculated in the previous continuity equation. It should not be confused with the vertical physical velocity which is utilized for post processing purposes.

Delft3D-FLOW uses the alternating direction implicit (ADI) method to integrate shallow water equations in time. The ADI method splits one time step into two phases, in which each phase makes up half of a time step. In both phases, all terms of the model equations are solved in a consistent way with at least second order accuracy in space (Deltares, 2011). It also uses three different spatial discretizations (in terms of advection): WAQUA-Scheme, Cyclic Method, and the Flooding Scheme.

Delft Dashboard's Tropical Cyclone Toolbox that computes the wind field and pressure drop generated by a cyclone was used to simulate the storm surges (Deltares, 2011).

This tool is based on the wind enhanced scheme (Deltares, 2009). The wind field is generated based on the analytical cyclone model of Holland (1980) that was further improved by introducing asymmetry. Holland's model assumes that for a generic tropical cyclone, the surface pressure field follows a modified rectangular hyperbola, as a function of radius, given by (Xie et al., 2006):

$P(r)=P_{C}+\left(P_{n}-P_{C}\right) \exp ^{-\left(R_{\max } / r\right)^{B}}$

and the velocity $V(r)$ at a distance $r$ from the hurricane center, is 
$V(r)=\left[\frac{B}{\rho_{a}}\left(\frac{R_{\max }}{r}\right)^{B}\left(P_{n}-P_{c}\right) \exp ^{-\left(R_{\max } / r\right)^{B}}+\left(\frac{r f}{2}\right)^{2}\right]^{1 / 2}-\frac{r f}{2}$

where $P_{n}$ is the ambient surface pressure, $P_{c}$ is the hurricane central surface pressure, $R_{\max }$ is the radius of maximum wind, $f$ is the Coriolis parameter, $\rho_{a}$ is the air density, and $B$ is a hurricane-shape parameter (ranging from 1 to 2.5). The computed winds are then adjusted to account for the asymmetry introduced by the interaction of the cyclone with the steering flow by adding the translatory movement of the cyclone to the existing wind field.

Other formulations are found in the literature, as per example Madsen and Jakobsen (2004), which also includes statistical forecast models for forecasting of the cyclone track and maximum wind speed and an uncertainty prediction procedure.

For a particular cyclone it is necessary to define its trajectory and associated time steps, maximum wind speed $\left(V_{\max }\right)$, maximum radius wind speed $\left(R_{\max }\right)$, and pressure drop $\left(P_{\text {drop }}\right)$. The intensity or maximum wind speed is defined as the system's maximum sustained winds. The radius of maximum winds is characterized as the distance from the center of the tropical cyclone to the location of the cyclone's maximum winds. In well-developed hurricanes the radius is found in the inner eyewall, while in subtropical systems, the radius occurs very frequently far away from the center. Lastly, the pressure drop represents the difference between the ambient and central pressures of a tropical system. The space varying wind and pressure on a spiderweb grid is added to the wind input which is then interpolated and combined in and around the cyclone (Deltares, 2011).

After analysis of the simulations carried out by the hydrodynamic model, a hazard assessment of the effect of an exacerbation of the typically observed results in that region was performed. Considering results from changes in the trajectories of the various historical storms, the analysis of the coast's response to storminess can be measured with the execution of different hypothetical scenarios. Simulations under conditions of uncertainty were generated, in other words, ensemble forecasting will be projected. As mentioned before, (Keim et al., 2004) suggest that an increase in frequency of really powerful storms is a great possibility; therefore, ensemble forecasting becomes an ever more essential tool for the proper planning and management of coastal regions.

In a chaotic system, like an atmosphere model, nonlinear errors can grow quickly. When dealing with natural systems, like weather and climatic conditions, they should be treated as a more statistical system rather than a deterministic one. Since the true state of the atmosphere can only be approximately observed, a statistical mean of a set of model forecasts, starting from slightly different initial states, reduces the impact of initial data uncertainties on the final forecast (Zhang and Krishnamurti, 1997). It has been proven that the Monte Carlo prediction results in a practical approximation to the stochastic dynamical technique and that an ensemble mean, i.e. average of the ensemble members, provides a more skillful forecast than the control run (member of the ensemble obtained from the best initial analysis) (Wesseling, 2009). In ensemble forecasting, the factors to be studied that are influential in the accuracy of a tropical cyclone prediction are the cyclone's track (position), the intensity of the cyclone, the radius of maximum winds, and its atmospheric pressure drop.

The idea for this phase was to analyze The Battery's coast when applying geographical shifts to the "normal" trajectories of the tropical cyclones, while simultaneously varying their meteorological variables. This is an especially tedious task if done manually; therefore, the application of a "Mouse Macro Recorder" is employed. The mouse macro recorder chosen was the Asoftech
Automation Macro Recorder, which allows for the automating of a series of computer tasks that may then be repeated. One can simulate or mimic mouse clicks and movements, keyboard presses, among other computer tasks. Another significant feature is its 'Schedule' feature, which allows the macro to run at a pre-defined time and repeat indefinitely (Asoftech, 2014). With the use of this recorder, the process of creating a randomized tropical cyclone can be repeated numerous times. A Microsoft Excel sheet was created to define certain reasonable limits for the values of the variables (latitude, longitude, $V_{\max }, R_{\max }$, and $P_{\text {drop }}$ ) witnessed in The Battery's case study. The variables are randomized according the limits to make sure that the ensemble members display correlations between them but at the same time, result in different outcomes.

The first variable established was the tropical cyclones' track position, latitudes and longitudes, which typically originate in the eastern tropic Atlantic Ocean and then tend to curve polarward with a later period of possible extratropical transitioning. The seasonal distribution of the tracks of extratropically transitioning cyclones is broken down into three periods: a low-latitude quiet early season, a high-latitude active mid season, and a mid-latitude active late season (Hart and Evans, 2001). Seeing that the simulations were executed from the end of July to beginning of August, corresponding to the beginning of the high-latitude active mid season, a transition needed to occur between the $40^{\circ} \mathrm{N}$ and $45^{\circ} \mathrm{N}$ latitude (Hart and Evans, 2001). In order to create this curved trajectory, the first imposed limitation was that the track points' longitude not surpass a longitudinal limit, selected between $-76^{\circ} \mathrm{W}$ and $-74^{\circ} \mathrm{W}$, represented in Fig. 1 as the red limitation. For each ensemble member simulation, a randomly selected value between this interval was considered as the tropical cyclones' turning point. The beginning of the cyclone path was selected to occur in any random value between $-61.5^{\circ} \mathrm{W}$ and $-77.5^{\circ} \mathrm{W}$ longitude (Fig. 1 ). If perhaps, the increasing longitude reaches this "peak", or turning point, the point following the turning point would continue in the opposite direction, that is, with a descending longitudinal value. This restriction forces the fictitious trajectories to curve toward the NY coastline before going too far westward, in order to simulate more "Sandy-like" cyclone trajectories. There is the possibility that the peak is never reached. In these instances, the trajectories resemble "straight lines" traveling in a northeastward direction. The longitudinal values were set to increase in random intervals between $0.5^{\circ}$ and $1.0^{\circ}$ if the point's longitudinal value occurs before reaching the turning point, and between $0.1^{\circ}$ and $0.5^{\circ}$ if the longitudinal value in question occurs after the turning point.

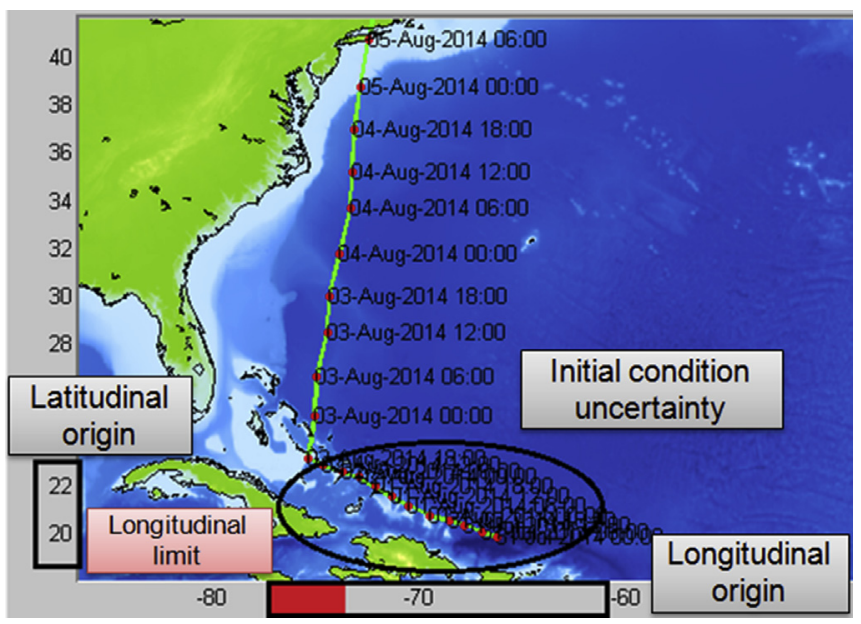

Fig. 1. Ensemble forecasting latitudinal and longitudinal considerations. 
The latitude for the beginning of the trajectories was selected to begin at any random value between the $19.5^{\circ} \mathrm{N}$ and $23.1^{\circ} \mathrm{N}$ (Fig. 1 ). For trajectory points situated before the longitudinal turning point, the increments were of random values between $0.2^{\circ}$ and $0.5^{\circ}$. For points located after the longitudinal turning point, the increments were of random values between $1.5^{\circ}$ and $2.0^{\circ}$. This is so that before the curving northward of the cyclone's path, towards the study area, the increments are smaller, having lesser displacements, therefore guaranteeing that the tropical cyclone does not travel too far. This is very commonly observed in the North Atlantic tropical cyclone paths. The trajectory points of the storm's path before turning northward, are more tightly spaced. The larger increments defined after the turning point are so that the cyclone path is certain to go through the case study's general area.

The following variable is related to the maximum sustained winds, i.e. the maximum velocity, was selected to begin at a random value between 26 and 45 knots ( 48.15 and $83.34 \mathrm{~km} / \mathrm{h}$ ), in the lower easterly tropics of the Northern Atlantic Basin, as is commonly observed in this region. In terms of the attributed values for the $V_{\max }$, while the tropical cyclone is approaching the United States' coast, before reaching the longitudinal turning point, the $V_{\max }$ was increased in random intervals between 2 and 10 knots (3.70 and $18.52 \mathrm{~km} / \mathrm{h}$ ). This is true, only if, the previous $V_{\max }$ value results in a value below 130 knots $(240.76 \mathrm{~km} / \mathrm{h})$. If the $V_{\max }$ reaches 130 knots ( $240.76 \mathrm{~km} / \mathrm{h}$ ) before the turning point, the value attributed to that point was of 130 knots $(240.76 \mathrm{~km} / \mathrm{h})$ until the selected longitudinal peak. This is to avoid that the simulated hurricanes reach unrealistically high wind speeds, not normally observed in this region. Once the path reaches its westerly peak, the $V_{\max }$ values were set to decrease in random intervals between 2 and 7 knots $(3.70$ and $12.96 \mathrm{~km} / \mathrm{h}$ ), to simulate normally observed tropical cyclone behavior. As the cyclone travels northward, the velocity typically begins to decline and the other variables have more of an influence on water level effects.

The radius of maximum winds, $R_{\max }$, was a much more difficult factor to define because of the lack of available data. The $R_{\max }$ was selected to begin with a random value between 25 and 60 nautical miles (46.30 and $111.12 \mathrm{~km}$ ), normally observed in the lower easterly tropics of the Northern Atlantic Basin. It was detected that as the tropical system moves northward, the higher the probability of its transitioning to an extratropical system; therefore, defining a latitudinal maximum was the most rational approach. This latitudinal maximum was defined as $38^{\circ} \mathrm{N}$ latitude. Along the trajectory, it is common for tropical cyclones to transform into extratropical systems around $35^{\circ} \mathrm{N}$ latitude (Hart and Evans, 2001). Although the transformed cyclones cannot have the same strengths witnessed earlier, over half of the systems undergo post-transitioning intensification and are most likely to impact the northeastern US and Canadian Maritimes (Hart and Evans, 2001). If the generated ensemble tropical cyclones path's latitude were positioned below the established $38^{\circ} \mathrm{N}$ latitude mark and the previously defined radius of maximum winds was selected with a value below or equal to 80 nautical miles ( $148.16 \mathrm{~km}$ ), the $R_{\max }$ was set to increase in random intervals between 2 and 5 nautical miles ( 3.70 and $9.26 \mathrm{~km}$ ). If the ensemble tropical cyclone path's point were positioned above the $38^{\circ} \mathrm{N}$ latitude mark and the previously defined radius was selected above 80 nautical miles ( $148.16 \mathrm{~km}$ ), the $R_{\max }$ was set to increase in random intervals between 10 and 20 nautical miles (18.52 and $37.04 \mathrm{~km})$, certifying that the input value not exceed 150 nautical miles $(277.80 \mathrm{~km})$. This is because, as the tropical cyclones transition to extratropical systems, the radius of maximum winds typically do not exceed 150 nautical miles $(277.80 \mathrm{~km})$.

Lastly, the ensemble members' pressure drop was defined. The pressure drop, $P_{d r o p}$, was set to begin with a random value between 2500 and $6000 \mathrm{~Pa}$. In the ensemble tropical cyclone path's region before the considered longitudinal turning point, the $P_{\text {drop }}$ was set to increase in random intervals between 100 and $500 \mathrm{~Pa}$, with an imposed limit of $8500 \mathrm{~Pa}$. After the longitudinal turning point, if the previous randomized $P_{\text {drop }}$ input was greater than $1500 \mathrm{~Pa}$, then it was set to decrease in random intervals between 100 and $500 \mathrm{~Pa}$. If the previous randomized $P_{d r o p}$ input was found to be below $1500 \mathrm{~Pa}$, then the resultant $P_{\text {drop }}$ was set to increase.

Since the simulation of tropical storms is of a very chaotic nature, nonlinear errors are common and the application of an ensemble forecast can be of great importance. The alterations of the initial values significantly influence the results; therefore, a statistical mean of a set of model forecasts can reduce the impact of the initial data uncertainties on the final result. With the application of the abovementioned conditions inputted onto a randomized Excel sheet, the outputs produced significant differences in solutions whose distributions do in fact match actual frequency of occurrence.

In a third stage, the numerical results were processed and analyzed, choosing to assess the results of water surface elevation in order to examine the envelope of water level, i.e. the maximum storm surge height at predefined locations of the coastal zone, for a given storm. This parameter was chosen since it can be easily linked to potential areas that could be affected by waves overtopping, flooding and coastal erosion. More precisely, for predefined locations, the Maximum Envelope of Water (MEOW) is obtained for a particular storm of a given category. Afterwards, it is possible to obtain the Maximum of the MEOWs (MOM). The MOM's value is selected for each storm category, among all the maximum storm surge heights of all simulated storms of the same category (Glahn et al., 2009). Basically, there is one MOM per storm category for each location. Thus, once the maximum envelope of water levels for a given storm category (MOM) is found, it is possible to assess the storm impact for the study area based on this variable. The results obtained are very important to predict the potential consequences of future storm events and to produce useful information that could be used in the design of emergency plans. In the case of The Battery, New York, the MEOWs and the MOMs were obtained with the recorded historical values. The vulnerability of the region to storminess is assessed based on real observational data which was consequently recreated.

\section{Historical storms}

With the aid of the NOAA's Historical Hurricane Tracks, considering an area with approximately $100 \mathrm{~km}$ radius of The Battery's observation station, a total of eighteen coastal storms were identified between 1915 and 2012, seen in Fig. 2. There was no interest in encompassing a larger time period because, for the hourly data obtained from the University of Hawaii Sea Level Center's database, there are no registered values for the analyzed observation stations before 1915.

Table 1 shows that the most frequent of the tropical systems observed are tropical storms. For the time span considered, there were four identified occurrences of tropical depressions, twelve identified occurrences of tropical storms, and two identified occurrences of tropical cyclones - categorized as Category 1. Again, hurricanes of higher categories were not registered. For this particular case, there is a $22.2 \%$ chance for the occurrence of a tropical depression, $66.6 \%$ for a tropical storm, and $11.1 \%$ for a Category 1 tropical cyclone.

\section{Application of the hydrodynamic model}

One domain was considered for The Battery, New York model. This domain was discretized (Fig. 3a and b) with a grid of a high 


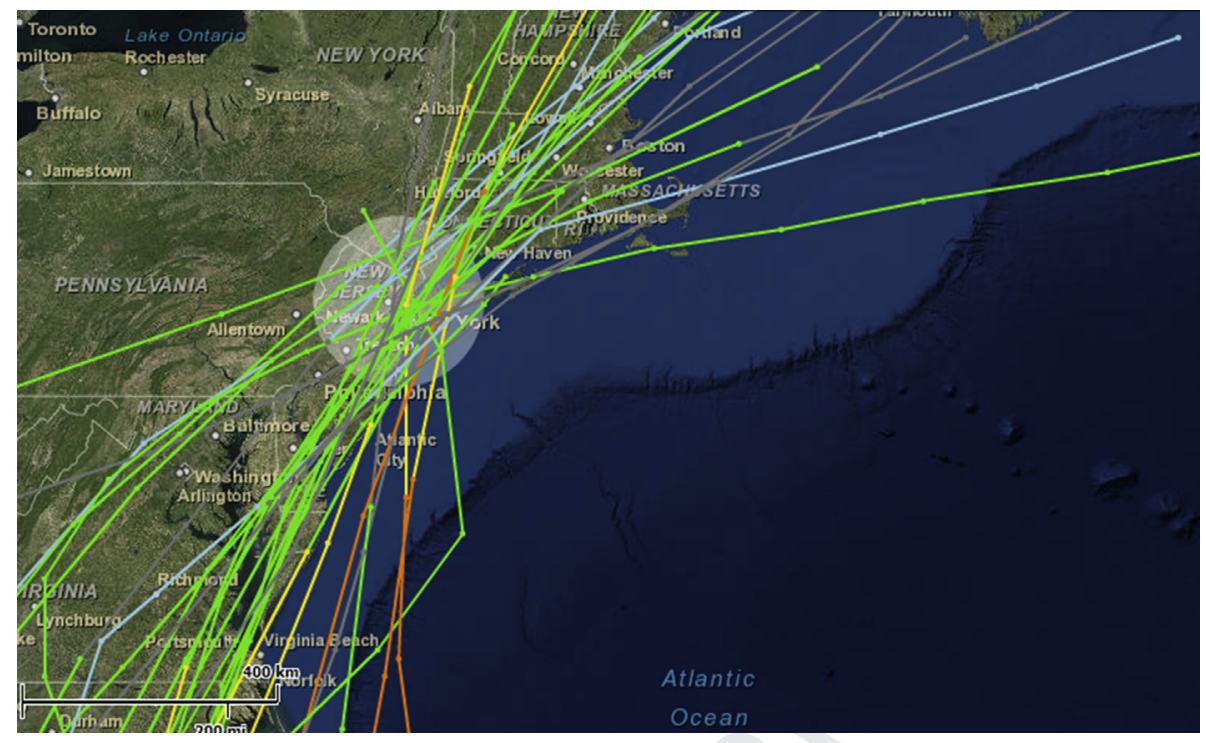

Table 1

Q1 History of coastal storms in a $100 \mathrm{~km}$ radius of New York, USA.

\begin{tabular}{|c|c|c|c|c|}
\hline Name & Year & Start date & End date & Velocity* $(\mathrm{km} / \mathrm{h})$ \\
\hline \multicolumn{5}{|c|}{ Tropical depression $<62$} \\
\hline Unnamed & 1945 & Sept 12 & Sept 20 & 55.56 \\
\hline Able & 1952 & Aug 18 & Sept 2 & 55.56 \\
\hline Chris & 1988 & Aug 21 & Aug 30 & 37.04 \\
\hline Gordon & 2000 & Sept 14 & Sept 18 & 46.30 \\
\hline \multicolumn{5}{|c|}{ Tropical Storm 62 to 118} \\
\hline Unnamed & 1915 & Jul 31 & Aug 5 & 92.60 \\
\hline Unnamed & 1924 & Sept 27 & Oct 1 & 111.12 \\
\hline Unnamed & 1934 & Jun 4 & Jun 21 & 74.08 \\
\hline Diane & 1955 & Aug 7 & Aug 21 & 74.08 \\
\hline Brenda & 1960 & Jul 28 & Aug1 & 83.34 \\
\hline Unnamed & 1961 & Sept 12 & Sept 15 & 64.82 \\
\hline Doria & 1971 & Aug 20 & Aug 29 & 92.60 \\
\hline Agnes & 1972 & Jun 14 & Jun 23 & 101.86 \\
\hline Bertha & 1996 & Jul 5 & July14 & 111.12 \\
\hline Floyd & 1999 & Sept 7 & Sept 17 & 111.12 \\
\hline Hanna & 2008 & Aug 28 & Sept 7 & 83.34 \\
\hline Irene & & Aug 8 & Aug 28 & 101.86 \\
\hline \multicolumn{5}{|c|}{ Tropical cyclone (category 1 ) 119 to 153} \\
\hline Belle & 1976 & Aug 6 & Aug 10 & 148.16 \\
\hline Gloria & 1985 & Sept 16 & Oct 2 & 138.90 \\
\hline
\end{tabular}

spatial resolution, with $412 \times 332$ grid cells spaced $850 \mathrm{~m}$.

All hydrodynamic domains are geo-referenced using the WGS 84 coordinate system. The bathymetry is based on a continuous terrain model for ocean and land with a spatial resolution of 30 arcseconds from General Bathymetric Chart of the Oceans, GEBCO_08 Grid (BODC, 2012). Open boundary conditions and initial conditions are given by TPXO 7.2, the current version of the global model of ocean tides (COAS, 2010). Spiderweb wind fields are generated using recorded data of atmospheric pressure, wind speed, storm trajectory and velocity (e.g., Tropical Storm Floyd which occurred in 1999 with a duration of 12 days, represented in Fig. 4).

\section{Results and discussion}

Considering the tropical cyclone occurrences for an understanding of how the tropical cyclones' affect The Battery's surrounding environment, the MEOWs and MOMs of The Battery's observation station along with other adjacent observation stations
(Fig. 3a) were found. Gathering eight different observation stations, all relatively near The Battery's study area, the peak of each station's sea level for the time interval of a given storm is obtained, i.e. its MEOW is obtained. With the help of the University of Hawaii Sea Level Center (UHSLC, 2014) database's hourly tide gauge data, it was possible to have some perception as to the storm tide heights expected in the midst of a tropical storm that occurs in the New York Harbor. This way, one can have an understanding of the worst possible scenarios expected of a storm surge for that location. The registered values of the MEOW (Table 2) and the MOM (Table 3) correspond to the following observation stations along the coast: Cape May, New Jersey (A), Atlantic City, New Jersey (B), The Battery, New York (C), Montauk, New York (D), New London, Connecticut (E), Newport, Rhode Island (F), Woods Hole, Massachusetts (G), and Nantucket Island, Massachusetts (H).

When simulating these historical storm tracks, the Delf3D models ran with duration times between 4 and 20 days, and each simulation lasted from about 40 to $60 \mathrm{~min}$. The simulations were carried out with the use of an Intel Core i7-4700MQ $2.40 \mathrm{GHz}$ processor. When developing the spiderweb wind field in DelftDashboard, if the maximum velocity (wind speed) is below $46.2 \mathrm{~km} / \mathrm{h}$, the generated spiderweb wind field will correspond to null velocities at that time step, and time steps thereafter. Because of this, tropical depressions are very rarely successfully recreated with the same precision as hurricanes or tropical storms. Also, because the data for the two hurricanes were missing (seen in column C), they too were not simulated. The only tropical systems that could possibly be simulated with known success would be the tropical storms. From a total of 18 coastal cyclones, only the 9 tropical storms were analyzed: Unnamed Tropical Storm [1934], Diane [1955], Brenda [1960], Unnamed Tropical Storm [1961], Doria [1971], Agnes [1972], Floyd [1999], Hanna [2008], and Irene [2011].

Knowing the exact location of The Battery's observation station one can obtain the maximum water level reached in that particular region as witnessed in Fig. $5 \mathrm{~d}$. Applying a zoom to the image in Fig. 5a, shown in Fig. 5b, the vectors corresponding to the spiderweb wind field for the exact time step of the highest recorded water are shown (in a greater scale).

Analyzing the results seen in Table 4, with a maximum percent error of $28.5 \%$ corresponding to 1955 's Tropical Storm Diane, it is clear that with the application of DelftDashboard's Tropical Cyclone's Toolbox, the simulated tropical storms are in fact valid. The 

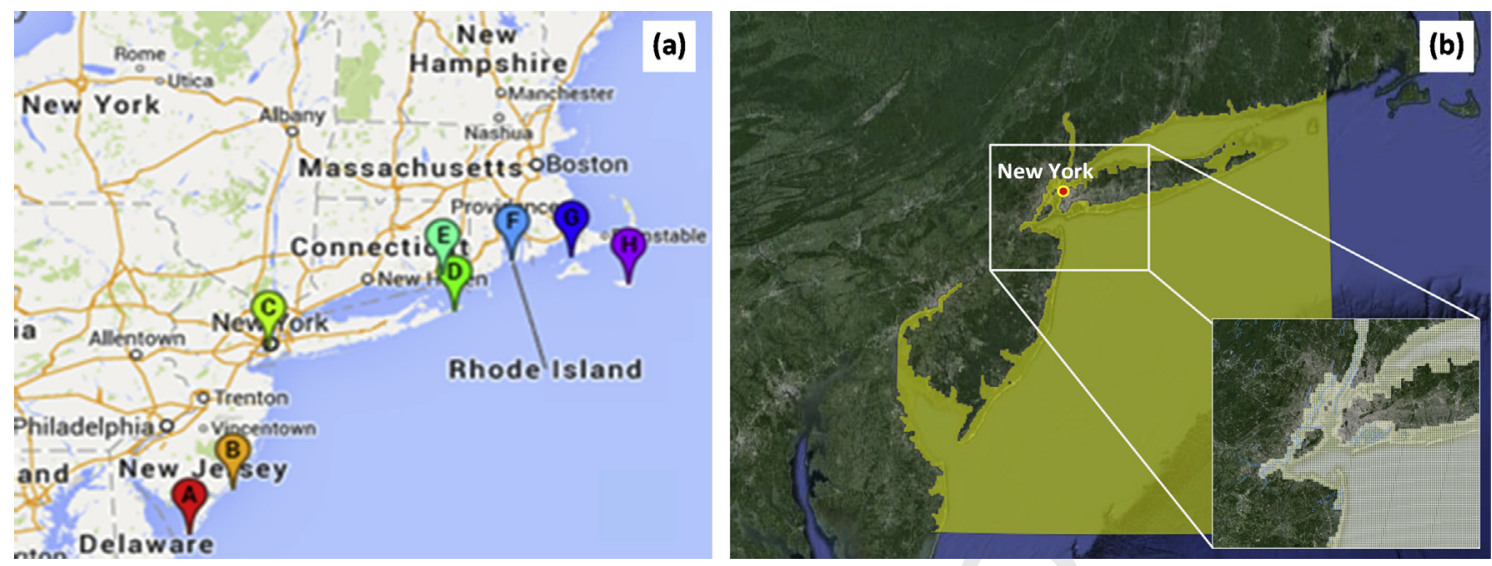

Fig. 3. Hydrodynamic domain generated for the NY scenarios: (a) observation stations considered for the US' northeastern coast analysis; (b) Northeastern coastal domain.

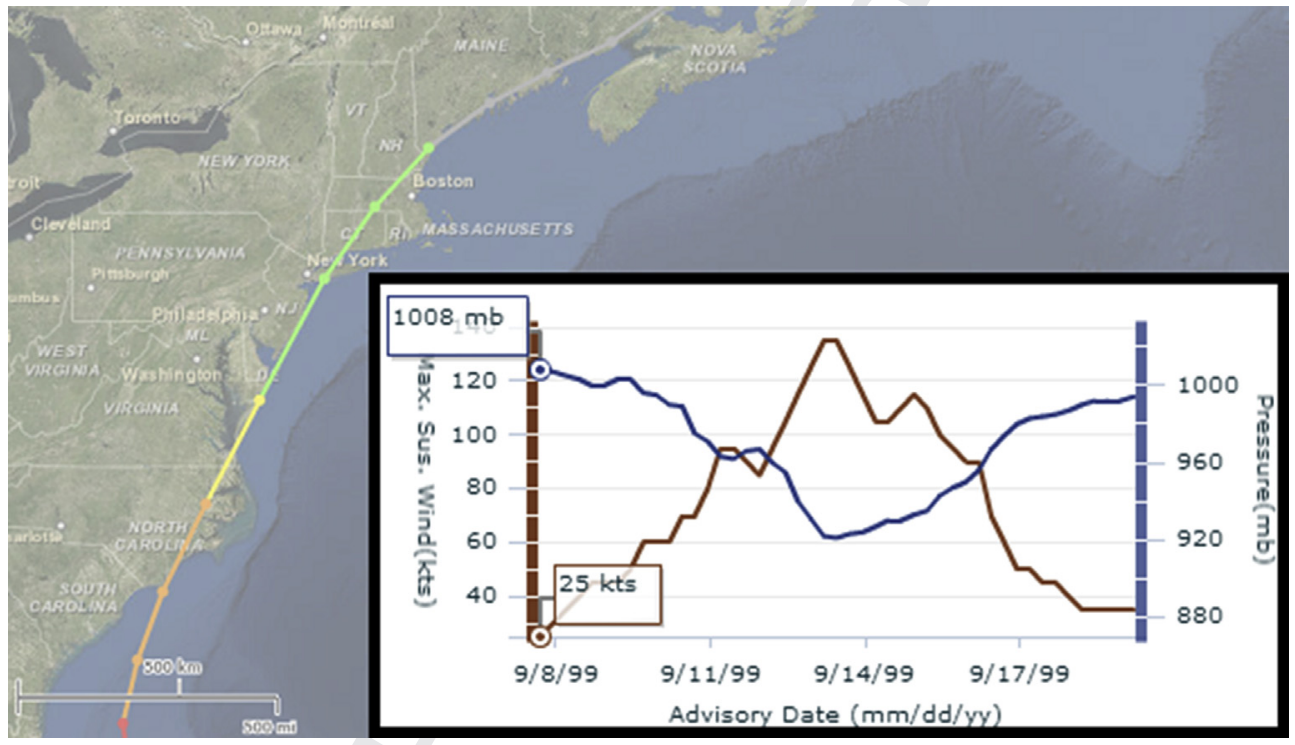

Fig. 4. Tropical Storm Floyd 1999 (NOAA, 2012): atmospheric pressure and wind velocity in the eye of the storm.

Table 2

Maximum Envelope of Water (MEOW) for the northeastern US coast (m).

\begin{tabular}{|c|c|c|c|c|c|c|c|c|c|}
\hline Name & Year & A & $\mathrm{B}$ & $\mathrm{C}$ & $\mathrm{D}$ & $\mathrm{E}$ & $\mathrm{F}$ & G & $\mathrm{H}$ \\
\hline \multicolumn{10}{|c|}{ Tropical depression } \\
\hline Unnamed & 1945 & - & 2.90 & 2.13 & - & 1.70 & 1.29 & - & - \\
\hline Able & 1952 & - & 2.48 & 1.90 & - & 1.76 & 1.33 & - & - \\
\hline Chris & 1988 & 1.74 & 2.63 & - & 1.65 & 1.57 & 1.41 & 1.29 & 1.45 \\
\hline Gordon & 2000 & 1.70 & 2.44 & 1.64 & 1.54 & 1.49 & 1.15 & 1.10 & \\
\hline \multicolumn{10}{|c|}{ Tropical storm } \\
\hline Unnamed & 1915 & - & 1.89 & - & - & - & - & - & - \\
\hline Unnamed & 1924 & - & 2.25 & - & - & - & - & - & - \\
\hline Unnamed & 1934 & - & 1.89 & 1.66 & - & - & - & - & - \\
\hline Diane & 1955 & - & 2.28 & 2.02 & - & 1.73 & 1.45 & - & - \\
\hline Brenda & 1960 & - & 2.01 & 1.90 & 1.89 & 1.94 & 1.54 & 1.44 & - \\
\hline Unnamed & 1961 & - & 2.07 & 1.66 & 1.44 & 1.51 & 1.18 & 1.13 & - \\
\hline Doria & 1971 & - & 1.87 & 1.94 & 1.51 & 1.54 & 1.15 & 1.14 & 1.28 \\
\hline Agnes & 1972 & 1.68 & 2.28 & 2.16 & - & 2.12 & 1.73 & 1.68 & 1.55 \\
\hline Bertha & 1996 & 1.76 & 2.41 & - & 1.85 & 1.86 & 1.54 & 1.58 & 1.49 \\
\hline Floyd & 1999 & 2.11 & 2.58 & 2.13 & 1.79 & 1.79 & 1.20 & - & 1.50 \\
\hline Hanna & 2008 & 1.80 & 1.99 & 1.36 & 1.71 & 1.60 & 1.24 & 1.26 & 1.40 \\
\hline Irene & 2011 & 2.54 & 2.74 & 3.09 & 2.38 & 2.55 & 2.02 & 1.86 & 1.76 \\
\hline \multicolumn{10}{|c|}{ Tropical cyclone } \\
\hline Belle & 1976 & 1.84 & 2.36 & - & 1.75 & 1.73 & 1.38 & 1.34 & 1.53 \\
\hline Gloria & 1985 & 2.61 & 3.31 & - & 2.03 & 2.43 & 1.58 & 1.89 & 1.47 \\
\hline
\end{tabular}

Table 3

Maximum of the MEOW (MOM) for the northeastern US coast ( $\mathrm{m}$ ).

\begin{tabular}{lllllllll}
\hline Name & A & B & C & D & E & F & G & H \\
\hline Tropical depression & 1.74 & 2.90 & 2.13 & 1.65 & 1.76 & 1.41 & 1.29 & 1.45 \\
Tropical storm & 2.54 & 2.74 & 3.09 & 2.38 & 2.55 & 2.02 & 1.86 & 1.76 \\
Tropical cyclone & 2.61 & 3.31 & - & 2.03 & 2.43 & 1.58 & 1.89 & 1.53 \\
\hline
\end{tabular}

use of a very dense grid can make it as though the discretization error is minimized. Of course that the implementation of a small curvilinear grid in the area of interest nested into a coarser model would have produced better and faster results, but as it is witnessed, the results seen in the table below can come quite close regardless of that fact.

Subtracting the values of the tidal influences at the point of each storm's occurrence from the observed and simulated mean seal level, the observed and simulated storm surge can be compared. Most of the results averaged between a 13 to 28 percent error. Two simulations, Doria [1971] and Agnes [1972], were able to reproduce storm surges with great accuracy, with 1.794 and 2.837 percent error respectively. Considering the example with the smallest resulting percent error, Tropical Storm Doria, the predicted storm 


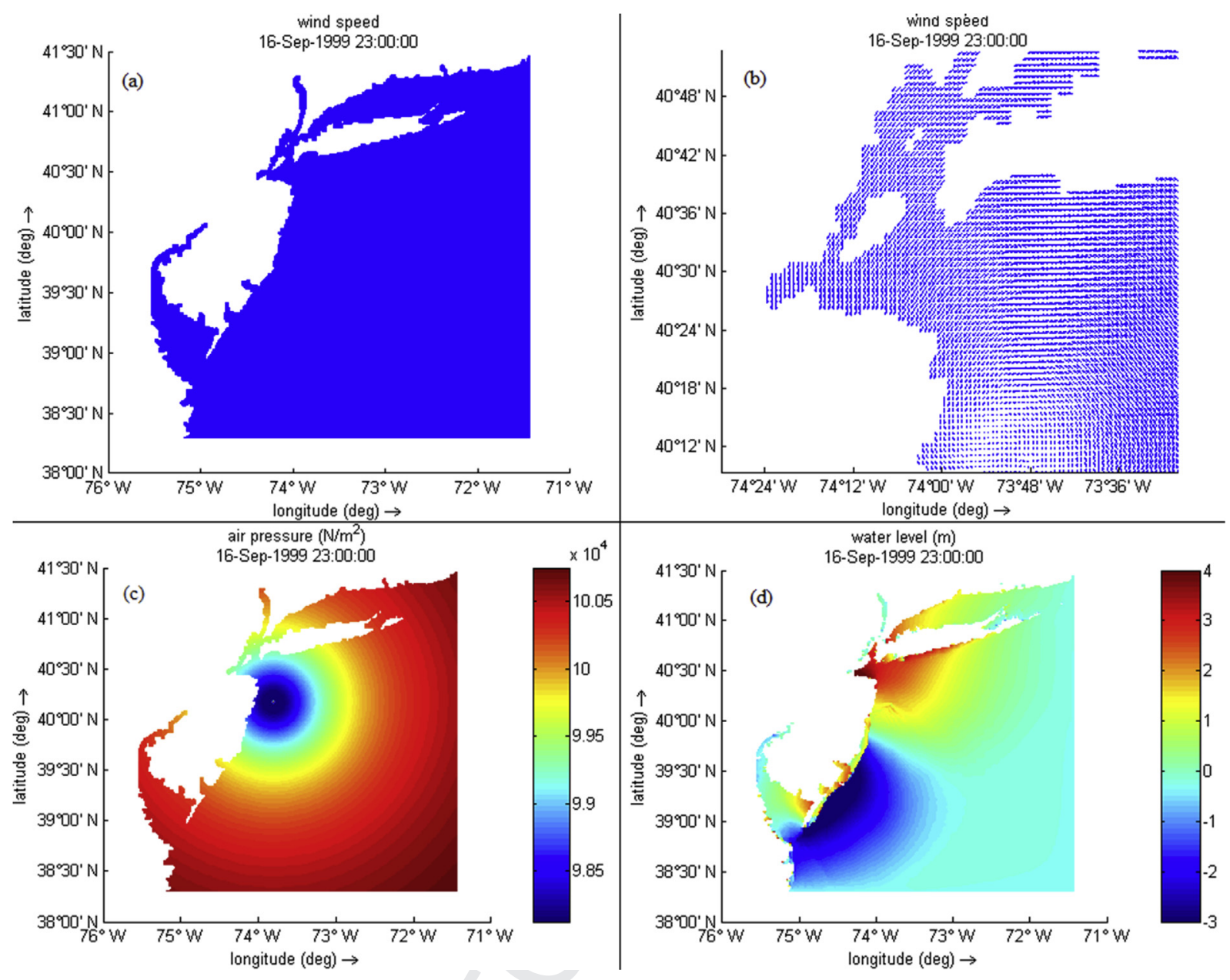

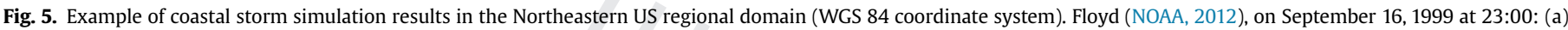
Wind field; (b) Wind field (zoom); (c) Atmospheric pressure in N/m2; (d) Water levels in meters.

Table 4

Values of the observed vs. simulated storm surge for the battery, NY (m).

\begin{tabular}{|c|c|c|c|c|c|c|c|}
\hline Name & Year & Observed MSL (m) & Simulated MSL (m) & Without wind field (m) & Observed Surge(m) & Simulated Surge(m) & Percent Error (\%) \\
\hline Unnamed & 1934 & 1.66 & 1.25 & 0.09 & 1.57 & 1.17 & 26 \\
\hline Diane & 1955 & 2.02 & 2.17 & 1.47 & 0.55 & 0.71 & 29 \\
\hline Brenda & 1960 & 1.90 & 2.24 & 0.03 & 1.87 & 2.21 & 18 \\
\hline Unnamed & 1961 & 1.66 & 1.85 & 0.82 & 0.84 & 1.03 & 23 \\
\hline Doria & 1971 & 1.94 & 1.98 & -0.52 & 2.45 & 2.50 & 2 \\
\hline Agnes & 1972 & 2.16 & 2.23 & -0.16 & 2.33 & 2.39 & 3 \\
\hline Floyd & 1999 & 2.13 & 2.48 & -0.52 & 2.64 & 3.00 & 13 \\
\hline Hanna & 2008 & 1.36 & 1.81 & -0.30 & 1.65 & 2.10 & 27 \\
\hline Irene & 2011 & 3.09 & 3.44 & 0.71 & 2.38 & 2.73 & 15 \\
\hline
\end{tabular}

surge reaches $2.496 \mathrm{~m}$, a value exceptionally close to the actually observed storm surge of $2.452 \mathrm{~m}$. One can conclude that because the application of DelftDashboard and Delft3D-FLOW to the situation of The Battery was so successful, its implementation to other locations can be equally successful.

With the application of the mouse recorder, after recording the first simulation, the program ran for 241 times. With the elimination of dubious data, 232 of the 241 created ensemble members were successfully analyzed. Considering a small area within the grid corresponding to the New York/New Jersey Harbor, with the application of a simple Matlab script, the maximum of the mean sea level (MSL) was obtained for all ensemble members for the specific area. The graph depicted in Fig. 6 shows the results for the maximum MSLs for the area surrounding the harbor for the duration of the simulation. This corresponds to the MEOW of each of the simulated storms. Of the 232 ensemble members, 175 members resulted in less than 7-m of MSL, 149 members resulted in less than 6-m, 120 members resulted in less than 5-m, and 109 members resulted in less than 4-m. This means that the 7, 6, 5, and 4-m MSL level limit resulted in enclosing $75.43 \%, 64.22 \%, 51.72 \%$, and $46.98 \%$ of the total ensemble members respectively. In the situations where the randomly created tropical cyclone trajectory did not even approach the case study area, the resulting mean sea level was of about $1.3 \mathrm{~m}$. Only 4 of the total 232 ensemble members (1.72\%) were unaffected by the simulated tropical cyclones.

Of all the simulated storms, the one that directly hits the New 


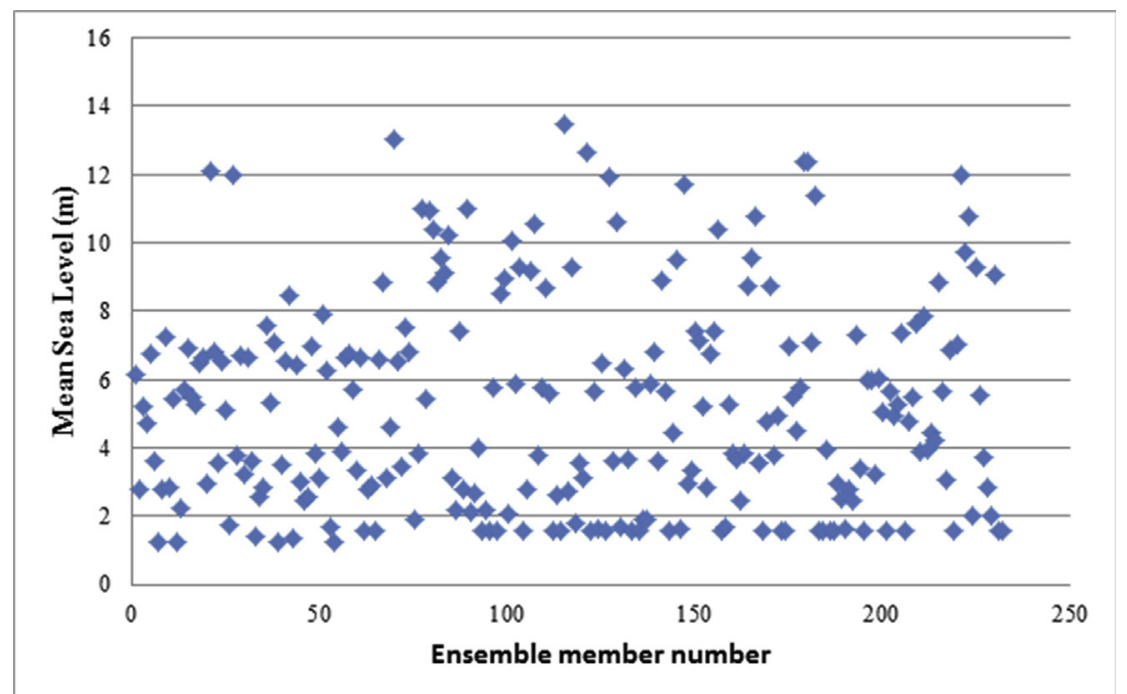

Fig. 6. Ensemble members' results - MSL (m).

York/New Jersey Harbor in a perpendicular fashion, results in a maximum MSL of 13.5 m on August 6th, 2014 at 7:00 AM. Because the trajectory's points are only defined every $6 \mathrm{~h}$, the closest results time step found for the 7:00 AM occurrence was the 6:00AM. At 6:00AM, the following data was randomly generated: latitude of $38.8^{\circ} \mathrm{N}$, longitude of $74.5^{\circ} \mathrm{W}, V_{\max }$ of 109.0 knots $(201.87 \mathrm{~km} / \mathrm{h}), R_{\max }$ of about 100 nautical miles ( $185.2 \mathrm{~km})$, and $P_{\text {drop }}$ of about $6000 \mathrm{~Pa}$. This storm trajectory did reach 130 knots $(240.76 \mathrm{~km} / \mathrm{h})$ a couple of days preceding its arrival to the $\mathrm{NY} / \mathrm{NJ}$ coast, classifying it as a Category 4 hurricane. This aggravation of the wind speed and atmospheric pressure can potentially be reached, resulting in truly devastating effects. The ensemble members had 22 tropical cyclone trajectories that surpassed the $10-\mathrm{m}$ mark (9.48\%). While the probability is small, the danger still exists. If the mere swell from Hurricane Sandy was able to produce wave heights of almost $10 \mathrm{~m}$, resulting in damages that to date are still not fully recovered, the recorded $13.5-\mathrm{m}$ wave resulting from a direct hit can have even worse consequences.

It is important to note that the ensemble forecasting executed is at a very small scale. There are programs better capable for analyzing this topic. For example, the United States' National Weather Service's Sea, Lake, and Overland Surges from Hurricanes (SLOSH) program has a Probabilistic Surge (P-Surge) application that incorporates statistics of past forecast performances automatically and generates an ensemble of SLOSH runs based on distributions of track, intensity, and size errors (NOAA, 2014). These models, of course, are a lot more computationally efficient and are able to resolve complex intricacies like inland flooding, the overtopping of barrier systems, deep passes between bodies of water, etc. Nevertheless, the application of this kind of ensemble forecasting does contribute for a comprehensive view of the vulnerability of the coastal regions being studied.

The vulnerability of the coast was evaluated by finding the maximum envelope of water (MEOW) for each of the ensemble storm simulations and consequently obtaining the maximum of each category (MOM). The MOMs for each of the categories indicates the location's vulnerability (maximum sea level expected), as seen in Table 5. In this analysis there were 147 hurricanes, 55 tropical storms, and 30 tropical depressions produced. Because the tropical cyclones were "forced" to pass directly through the desired area of interest, it was expected that there would be more observed hurricanes than usual. The purpose of this application was just that
- to study how the water levels correspond to an exacerbation of typically observed data, predicting potentially catastrophic tropical cyclones. This intensification resulted in a Maximum of the MEOW of $13.5 \mathrm{~m}$. For the Tropical Storm category, the maximum mean sea level for the MEOWs resulted in $6.3 \mathrm{~m}$. This is double the MSL of the results analyzed for Tropical Storm Irene given in Table 1. Lastly, the Tropical Depression category resulted in a maximum mean sea level of $1.6 \mathrm{~m}$. The tropical depressions in this analysis represent the results of tropical systems observed outside the grid area, generating results with merely tidal influences, or very small water level variations due to swells.

\section{Conclusions}

In the case study area, the resulting simulations of the various historical coastal storms affecting the US' eastern coast were a success, with all of them resulting in less than 30 percent error. The differences observed can be due to the fact that data aren't always retrieved with precision or the fact that normally, storm wind fields are not always symmetric which can in fact hinder the results. The lack of information, especially when dealing with systems dating back many years, increases the difficulty of recreating these tropical storms. For example, the 1934 Unnamed Tropical Storm's only available data were the maximum sustained surface winds (wind speed). The input of the radius of maximum winds proved to be difficult to obtain. The only tropical storms to have these data available were the two most recent tropical storms, Hanna and Irene. Because the region being studied can be the transition zone for tropical systems becoming extratropical systems, the radius of maximum winds can be a significant factor. The forecasting of possible future tropical systems was executed. In this ensemble forecasting work, $63.36 \%$ of the 232 total ensemble members produced were hurricanes, $23.71 \%$ were tropical storms, and $12.93 \%$ were tropical depressions. This intensification of the typically

Table 5

Ensemble simulations maximum of MEOWS (MOM).

\begin{tabular}{lcc}
\hline Category & No. of occurrences & MOM $(\mathrm{m})$ \\
\hline Tropical depression & 147 & 13.5 \\
Tropical storm & 55 & 6.3 \\
Tropical cyclone & 30 & 1.6 \\
\hline
\end{tabular}


observed data resulted in a Maximum of the MEOW value of $13.5 \mathrm{~m}$ for the hurricane category, $6.3 \mathrm{~m}$ for the tropical storm category, and lastly $1.6 \mathrm{~m}$ for the tropical depression category. Forcing of the tropical cyclones to pass directly through the desired area made it possible to study how the water levels correspond to an exacerbation of the typically observed data.

Nevertheless, it is clear that the application of Delft Dashboard's Tropical Cyclone's Toolbox does in fact produce valid tropical storm simulations. With such a user-friendly interface with relatively quick simulation times, one can reproduce a tropical storm and assess the outputting water levels, contributing in the planning and management of the coastal zones. Because the New York results were so successful, there is more confidence and value in the results produced for other coasts. Using an identical methodology, the application of this numerical tool in the Portuguese coast is in progress and the results will be published soon.

\section{References}

American Association of Port Authorities, 2014. Port Industry Statistics - Port Industry Information - AAPA. Retrieved from Aapa-ports.org. http://www.aapaports.org/Industry/content.cfm?ItemNumber $=900$.

Asoftech, 2014. Mouse Keyboard Macro Recorder - Automation Software. Retrieved from Asoftech.com. http://www.asoftech.com/ata/.

Bloomberg, T.C., 2013. A Stronger, More Resilient New York (New York).

BODC, 2012. Bathymetry Data from the GEBCO_08 Grid (available in the tool DeftDashboard).

COAS, 2010. TPXO 7.2-Global Inverse Tide Model (available in the tool DeftDashboard)

Deltares, 2009. Wind Enhanced Scheme (WES) for Cyclone Modelling. User Manual Version 3.00.

Deltares, 2011. User Manual Delft3D-flow. Hydro-morphodynamics. Version: 3.15, Netherlands.

Deltares, 2012. DelftDashboard - OpenEarth - Deltares Public Wiki (accessed 24.07.12.). http://publicwiki.deltares.nl/display/OET/DelftDashboard.

FEMA, 2003. U.S. Department of Homeland Security, URS, US Army Corps of Engineers. Slosh Display Training: Sea, Lake, and Overland Surge from Hurricanes. National Oceanic and Atmospheric Administration, USA.

Glahn, B., Taylor, A., Kurkowski, N., Shaffer, W.A., 2009. The role of the SLOSH model in national weather service storm surge forecasting. Natl. Weather Dig. 33 (1) $3-14$.

Hart, R.E., Evans, J.L., 2001. A climatology of the extratropical transition of Atlantic tropical cyclones. J. Clim. 14, 546-564.

Holland, G.J., 1980. An analytic model of the wind pressure profiles in hurricanes. Mon. Weather Rev. 108, 1212-1218.

IM, 2008. Tropical Cyclones accessed 16.10.12., in Portuguese. http://www.meteo.pt/ pt/areaeducativa/fenomenos_meteorologicos/ciclones_tropicais/index.html.

Keim, B.D., Muller, A.R., Stone, G.W., 2004. Spatial and temporal variability of coastal storms in the North Atlantic Basin. Mar. Geol. 210, 7-15.

Klemas, V.V., 2009. The role of remote sensing in predicting and determining coastal storm impacts. J. Coast. Res. 25, 1264-1275.

Kron, W., 2012. Coasts: the high-risk areas of the world. Nat. Hazards, 0921-030X Springer, 20pp.

Landsea, C., Goldenberg, S., 2004. Tropical Cyclone FAQ. Retrieved from. Aoml.noaa gov. http://www.aoml.noaa.gov/hrd/weather_sub/faq.html. August 13.

Madsen, H., Jakobsen, F., 2004. Cyclone induced storm surge and flood forecasting in the northern Bay of Bengal. Coast. Eng. 51 (4), 277-296. ISSN 0378-3839. http://dx.doi.org/10.1016/j.coastaleng.2004.03.001.

NHC, 2015. National Weather Service. Glossary of National Hurricane Center Terms. http://www.nhc.noaa.gov/aboutgloss.shtml.

NOAA, 2012. Historical Hurricane Tracks. (2014). Retrieved from Csc.noaa.gov. http://csc.noaa.gov/hurricanes/\#.

NOAA, 2014. Tropical Cyclone Climatology. (2014). Retrieved from Nhc.noaa.gov. http://www.nhc.noaa.gov/climo/. March 19.

NPCC, 2013. Climate Risk Information 2013 (June). http://www.nyc.gov/html/ planyc2030/downloads/pdf/npcc climate risk information_2013 report.pdf.

Nott, J., 2006. Tropical cyclones and the evolution of the sedimentary coast of northern Australia. J. Coast. Res. 22, 49-62.

Rego, J.L., Li, C., 2009. On the importance of the forward speed of hurricanes in storm surge forecasting: a numerical study. Geophys. Res. Lett. 36 (L07609), $1-5$.

UHSLC, 2014. Retrieved from Uhslc.soest.hawaii.edu: http://uhslc.soest.hawaii.edu/ data/faq.

Weisse, R., von Storch, H., Niemeyer, H.D., Knaack, H., 2012. Changing North Sea storm surge climate: an increasing hazard? Ocean Coast. Manag. 68, 58-68.

Wesseling, P., 2009. Principles of Computational Fluid Dynamics. Spinger Verlag, Berlin.

Xie, L., Bao, S., Pietrafesa, L.J., Foley, K., Fuentes, M., 2006. A real-time Hurricane surface wind forecasting model: formulation and verification. Mon. Weather Rev. 134, 1355-1370.

Zhang, Z., Krishnamurti, T., 1997. Ensemble forecasting of hurricane tracks. Bull. Am. Meterol. Soc. 78 (Issue no. 12), 2785-2795. 